the current regimen, are superior in comparison to alternative preventive therapy options. Nevertheless, consistent evaluation of drug sensitivity tests is imperative in an ongoing evaluation of this decision.

In conclusion, our study is based on valid material and on actual circumstances, and its outcome can provide some evidence to yield of screening of potential immigrants from Ethiopia, and hopefully from other African countries.

\section{Z. Mor*, Y. Lerman ${ }^{\#,+}$ and A. Leventhal ${ }^{*,+}$}

${ }^{*}$ Public Health Services, Ministry of Health, ${ }^{+}$Braun School of Public Health of Hadassah and the Hebrew University, Jerusalem, "Preventive Medicine Dept, Clalit Health Services, and School of Public Health, Sackler Faculty of Medicine, Tel Aviv University, Tel Aviv, Israel.

\section{STATEMENT OF INTEREST}

None declared.

\section{REFERENCES}

1 Bhuniya S. Pre-immigration screening for pulmonary tuberculosis: the unanswered questions. Eur Respir J 2009; 33: 221-222.

2 Mor Z, Lerman Y, Leventhal A. Pre-immigration screening process and pulmonary tuberculosis among Ethiopian migrants in Israel. Eur Respir J 2008; 32: 413-418.

3 Institute of Medicine. Ending neglect: the elimination of tuberculosis in the United States. Washington, DC, National Academies Press, 2000; pp. 87-97.

4 Centers for Disease Control and Prevention, Screening for tuberculosis and tuberculosis infection in high-risk populations: recommendations of the Advisory Council for the Elimination of Tuberculosis. MMWR 1995; 44: 18-34.

5 Broekmans JF, Migliori GB, Rieder HL, et al. World Health Organization, International Union Against Tuberculosis and Lung Disease, and Royal Netherlands Tuberculosis Association Working Group. European framework for tuberculosis control and elimination in countries with a low incidence. Recommendations of the World Health Organization (WHO), International Union Against Tuberculosis and Lung Disease (IUATLD) and Royal
Netherlands Tuberculosis Association (KNCV) Working Group. Eur Respir J 2002; 19: 765-775.

6 Menzies D. Screening immigrants to Canada for tuberculosis: chest radiography or tuberculin skin testing? CMAJ 2003; 169: 1035-1036.

7 American Thoracic Society, Centers for Disease Control Treatment of tuberculosis and tuberculosis infection in adults and children. Am J Respir Crit Care Med 1994; 149: 1359-1374.

8 Marhez C, Bangala Y, Bady P, Zellweger JP. Active screening for pulmonary tuberculosis by chest $\mathrm{X}$-ray among immigrants at the Swiss border. Swiss Med Wkly 2007; 137: 649-654.

9 Nakamura K, Ohmi A, Kurihara T, Suzuki S, Tadera M. Studies on the diagnosis value of $70 \mathrm{~mm}$ radiophotograms by mirror camera and reading ability of physicians. Kekkaku 1970; 45: 121-128.

10 van Cleeff MRA, Kivihya-Ngugga LE, Meme $H$, Odhiambo JA, Klaster PR. The role and performance of chest X-ray for the diagnosis of tuberculosis: a cost effectiveness analysis in Nairobi, Kenya. BMC Infect Dis 2005; 5: 111.

11 Menzies D. Chest radiography versus tuberculin skin testing for tuberculosis screening of immigrants to Canada. www.cmaj.ca/cgi/content/full/169/10/1035/ DC1. Date last accessed: September 29, 2008.

12 Coker RJ, Bell A, Pitman R, Hayward A, Watson J. Screening programmes to tuberculosis in new entrants across Europe. Int J Tuberc Lung Dis 2004; 8: 1022-1026.

13 Saraiya M, Cookson ST, Tribble $\mathrm{P}$, et al. Tuberculosis screening among foreign born persons applying for permanent US residence. Am J Public Health 2002; 92: 826-826.

14 Pang SC, Harrison RH, Brearley J, Jegathesan V, Clayton AS. Tuberculosis surveillance in immigrants through health undertaking in western Australia. Int $J$ Tuberc Lung Dis 2000; 4: 232-236.

15 Richards B, Kozak R, Brassard P, Menzies D, Scwartzman K. Tuberculosis surveillance among new immigrants in Montreal. Int J Tuberc Lung Dis 2005; 9: 858-864.

\title{
Left ventricular dysfunction in patients with interstitial lung diseases
}

\section{To the Editors:}

The paper by PAPADOPOULOS et al. [1] describes the failure of systolic left ventricular (LV) function in patients with idiopathic lung fibrosis (IPF).

Not much is known about LV systolic and diastolic function failure in IPF patients or its influence on rates of survival. In 1998, VizZA et al. [2] examined a large group of patients with advanced lung diseases and estimated that $6 \%$ of them had LV failure, in particular patients with primary pulmonary hypertension and Eisenmenger's syndrome. However, in a patient group with interstitial lung diseases (ILD) the proportion was lower and reached $3.6 \%$.

In 2007, we studied LV systolic function in 18 patients with lung fibrosis and heavy respiratory insufficiency [3]. The patients 
fulfilled the American Thoracic Society (ATS)/European Respiratory Society (ERS) criteria for lung transplantation. In this group there were nine patients with IPF, four patients with advanced allergic hypersensitivity alveolitis, three patients suffered from lung fibrosis in a course of connective tissue diseases and two patients had silicosis. The control group consisted of 22 patients with ILD that had been evaluated for lung transplantation, but did not meet all ATS/ERS criteria for intervention. Similarly to PAPADOPOULOS et al. [1], we excluded patients with coexistent heart-circulation diseases or other diseases which might affect the LV function. The echocardiogram included two-dimensional examination with colour-doppler and pulsative parameters according to the recommendation of the American Echocardiography Society [4].

The presented spirometric and blood gas parameters were lower in our patient group in comparison to those presented by PAPADOPOULOs et al. [1] (forced vital capacity (FVC): $37 \pm 15$ versus $61 \pm 15 \%$ predicted; arterial oxygen tension: $47 \pm 8$ versus $62 \pm 6 \mathrm{mmHg}(6.2 \pm 1.0$ versus $8.3 \pm 0.8 \mathrm{kPa}))$. Also, the achieved distance in a 6-min walking test $(6 \mathrm{MWT})$ was shorter $(255 \pm 180$ versus $450 \pm 147 \mathrm{~m}$ ). Unlike PAPADOPOULOS et al. [1], we found substantial differences both in LV morphology and LV function between the study and the control groups. The end diastolic dimension of $\operatorname{LV}(4.4 \pm 0.7$ versus $4.9 \pm 0.4 \mathrm{~cm} ; \mathrm{p}=0.008)$, as well as $\mathrm{LV}$ volumes (end-systolic volume $26 \pm 12$ versus $41 \pm 20 \mathrm{~cm}^{3}$; $\mathrm{p}=0.01$ and end-diastolic volume $56 \pm 29$ versus $79 \pm 21 \mathrm{~cm}^{3}$; $\mathrm{p}=0.02$ ) were essentially different between the study and the control groups. Similarly to the study by PAPADOPOULOS et al. [1], we did not state differences in the intraventricular septum diameter between the researched groups. We found positive correlations between the distance in 6MWT and variables connected with LV morphology. Similarities were also found between spirometric parameters (forced expiratory volume in one second and FVC) as well as the results of blood gas measurements and data obtained by echcardiogram estimation of LV. Consequently, it can be noticed that factors limiting activity in the end-stage ILD correlate with echocardiogram findings of $\mathrm{LV}$ in those patients.

PAPADOPOUlos et al. [1] stated that the systolic function of the LV is preserved in patients with IPF. In our group, the systolic parameter of LV (estimated ejection fraction (EF)) was also satisfying (average EF $55.3 \pm 4.7 \%$ ). However, we showed that patients with more advanced stages of pulmonary fibrosis present changes in the geometry of LV. Additionally, the size and the volume of LV correlate with parameters describing impairment of pulmonary function and activity in these patients. Therefore, although we did not estimate diastolic function of LV, we can assume that morphological changes of $\mathrm{LV}$ in patients with pulmonary fibrosis might also lead to the failure of the diastolic function of the LV. In our study, almost $70 \%$ of patients presented signs of pulmonary hypertension. Pulmonary hypertension can be the reason for changes in left ventricle geometry caused by an enlarged and overloaded right ventricle.

The correlation between echocardiogram parameters and the impairment of pulmonary function in patients with interstitial lung disease indicates that the impairment of left ventricular function is of major importance in patients with end-stage interstitial lung disease.

\section{Jastrzebski*, J. Nowak", D. Ziora*, J. Wojarski", J. Kozielski*, L. Polonski ${ }^{\#}$ and M. Zembala\#}

*Dept of Lung Diseases and Tuberculosis, Silesian School of Medicine, and "Silesian Centre for Heart Diseases, Zabrze, Poland.

\section{STATEMENT OF INTEREST}

None declared.

\section{REFERENCES}

1 Papadopoulos CE, Pitsiou G, Karamitsos TD, et al. Left ventricular diastolic dysfunction in idiopathic pulmonary fibrosis: a tissue Doppler echocardiographic study. Eur Respir J 2008; 31: 701-706.

2 Vizza CD, Lynch JP, Ochoa LL, Richardson G, Trulock EP. Right and left ventricular dysfunction in patients with severe pulmonary disease. Chest 1998; 113: 576-83.

3 Jastrzebski D, Nowak J, Ziora D, et al. Left ventricular dysfunction in patients with interstitial lung diseases referred for lung transplantation. J Physiol Pharmacol 2007; 58: Suppl. 5, 299-305.

4 Quinones AL, Douglas PS, Foster E, et al. ACC/AHA clinical competence statement on echocardiography. J Am Coll Cardiol 2003; 41: 687-708.

DOI: $10.1183 / 09031936.00147208$

From the authors:

We thank D. Jastrzebski and coworkers for their interest in our work. The authors suggest that pulmonary hypertension may be the reason for changes in left ventricular (LV) geometry due to an enlarged and overloaded right ventricle. However, ventricular overload may be caused by an increase in pressure or volume, or a combination of both.

Resting LV systolic function is more severely depressed in patients with right ventricular (RV) volume overload compared with patients with RV pressure overload. Most studies have demonstrated that the underfilled left ventricle found in RV pressure overload conditions, such as idiopathic pulmonary fibrosis (IPF), has relatively preserved systolic function [1, 2]. Gото et al. [3] showed that increasing RV pressure by pulmonary artery constriction caused regional changes in systolic shortening in the anterior, posterior, and lateral walls of the left ventricle and the septum. Similar to RV volume overload, RV pressure overload distorts left ventricular end-diastolic geometry. In contrast to RV volume overload, with RV pressure overload, the left ventricle does not return to its normal shape in systole [4]. Angiographic and echocardiographic data from patients with chronic pulmonary hypertension have also shown abnormalities in septal geometry and motion [5]. Thus, we agree with D. Jastrzebski and coworkers that the left ventricle may undergo morphological changes in patients with IPF but we submit that overall systolic function is almost always preserved. LV systolic dysfunction, rarely present, is often due to coexisting severe right-sided heart failure with pulmonary vascular disease [2].

In IPF, impairment in early diastolic LV filling with compensatory increases in atrial systolic filling does not achieve 